\title{
COLORES, PALABRAS, SONIDOS, ESPACIO, TIEMPO: EN BUSCA DE LA OBRA DE ARTE TOTAL
}

\author{
Colors, words, sounds, space, time: "total work of art"
}

\author{
María José Fariña Busto ${ }^{l}$
}

\begin{abstract}
RESUMEN
Este artículo ofrece una visión del concepto de obra de arte total desde el punto de vista de ciertos artistas e historiadores que desarrollaron sus obras e ideas entre finales del siglo XIX y las primeras décadas del XX. Para ello, este trabajo se basa en las concepciones que sobre el arte y las diversas artes tenían algunos de ellos, estableciendo la relación entre la materia y los materiales a partir de los cuales se materializa la obra en cada una de ellas.
\end{abstract}

Palabras clave: Arte, interrelación de las artes, obra de arte total.

\begin{abstract}
This article gives a vision of the concept of "total work of art" from the point of view of certain artists and historians who developed their works and ideas between the end of the $19^{\text {th }}$ century and the first decades of the $20^{\text {th }}$ century. Therefore, this research is based on the conceptions about art and the various arts had some of them, establishing the relation between the material and the materials from which the work is materialized in each one of them.
\end{abstract}

Key Words: Art, interrelation of the arts, "total work of art".

\section{La idea de obra de arte total y la interrelación de las artes}

Al igual que la pintura, que ya con anterioridad había querido dejar de ser una obra fundamentalmente bidimensional para alcanzar la tercera dimensión, desde los inicios del siglo $\mathrm{XX}$, los conceptos tradicionalmente vinculados a las otras artes empezaron a cambiar. Así, en este momento, tampoco la escultura se conformaba con ser un volumen y quería abarcar el espacio; la música no solo quería tener el tiempo en sus manos, sino también ocupar el espacio; la poesía quiso hacerse música; en el teatro muchos vieron la posibilidad de aunar todas las ramas del arte, la luz generaba mundos y espacios donde la música, la palabra, la danza, la pintura, la escultura, la configuración arquitectónica de la propia escena constituían un conjunto artístico.

\footnotetext{
${ }^{1}$ Universidad de Vigo. Doctora en Arquitectura. España. Correo electrónico: pepa@coag.es Recepción: 10-10-2017. Aceptación: 23-04-2018.
} 
Algo más tarde, las instalaciones unían escultura y arquitectura, las intervenciones modificaban el espacio construido, el Land Art traspasó los muros para enlazar arte y paisaje, las Performances sacaron las actuaciones de los escenarios para aunarlas con la escultura (una escultura en movimiento más allá del de los "móviles" de Alexander Calder); los Happenings llevaron el teatro a cualquier lugar; el Body Art introdujo una ciencia, la cirugía, en el mundo del arte: el artista ya no quería representar, quería ser él mismo la propia obra de arte. Los ordenadores aumentaron las posibilidades de interacción: arquitecturas pintadas podían convertirse en mundos, en espacio virtuales donde los avatares sustituyen a los humanos en el juego de una vida inventada, a la carta.

La vida de las personas se convirtió en el "gran teatro del mundo", siempre en una búsqueda de la esencialidad del arte ligada al ser humano; ya no existían distintas artes, la vida se convertía en arte, la confluencia parecía total. Cuando algunos preconizaban la muerte del arte, éste resurge de las cenizas del sometimiento de una academia clásica y se enfrenta a una dirección única para diversificarse y entrelazar sus medios, materiales $\mathrm{y}$ formas.

“Il n’y a pas de sculpteurs seuls, de peinares seuls, d'architectes seuls. L'événement plastique s'accomplit dans une forme une au service de la poésie" (Moos, 1977, p. 327), palabras de Le Corbusier, pintor y arquitecto, más conocido por la segunda faceta, pero quien, durante toda su vida, dedicó algunas horas de sus días a la primera. Le Corbusier habla de síntesis y considera que la unidad:

Debe englobar todas las artes mayores, no es un aspecto exterior propio de determinadas construcciones. Es la presencia de ciertas formas y de ciertas imágenes fundamentales que califican toda actividad creadora: tanto la del arquitecto, como la del pintor, el escultor o el poeta (Moos, 1977, p. 329). ${ }^{2}$

El concepto de obra de arte total surge en Richard Wagner a mitad del siglo XIX y se convierte en tema de discusión en amplios círculos y por múltiples autores a lo largo de los años, quienes darán su visión particular al respecto. Será el género en el que trabaja el artista correspondiente el que presentará su primacía sobre los demás, ya sea arquitectura, música o cualquier otro.

\footnotetext{
${ }^{2}$ Todas las citas provenientes de textos originales en un idioma distinto del castellano han sido traducidas por la autora del artículo.
} 
Escenografía y música se funden en los dramas wagnerianos, una síntesis en la que se apoyarán los simbolistas Puvis de Chavannes, Gustave Moreau o Hodler, en su intención de superar las diferencias entre las distintas artes, basan sus obras en su propia subjetividad, en la experiencia emocional, quizás en esa "necesidad interior" de la que posteriormente hablará tanto el pintor Wassily Kandinsky.

En muchos artistas de finales del siglo XIX y principios del XX, se encuentra la fusión entre color y música; así, Emil Nolde relata: “¿No son los sueños como sonidos, y los sonidos como colores, y los colores como música? Yo amo la música de los colores" (Nolde, 1999, p. 100). Rimbaud, el poeta, irá más allá:

¡Inventé el color de las vocales! -A negro, E blanco, I rojo, O azul, U verde-. Regulé la forma y el movimiento de cada consonante y, con ritmos instintivos, me vanaglorié de inventar un verbo poético accesible, un día u otro, a todos los sentidos (Rimbaud, 1985, p. 45).

Lo anterior se asocia con el hermetismo simbólico, pues se establecen "las equivalencias entre colores y movimientos del alma" (Fagiolo, 1977, p. 111).

Andrei Nakov fundamenta la interrelación entre las artes, y el nacimiento del arte actual, en los descubrimientos científicos que se producen a partir de las investigaciones sobre las partículas atómicas y la teoría de la relatividad. El haber llegado al conocimiento de las partículas elementales, esencia universal, que permiten establecer la forma de la obra a partir de "un principio de constitución interno", lleva a hacer intercambiables los ámbitos de los diferentes campos artísticos, trabajando con el concepto y la teoría como parte integrante y fundamental de la propia obra. Para Nakov, "la perfección de la forma moderna se sitúa en la solidez de su construcción interna” (Nakov, 1989, p. 24).

Nakov establece la idea de fragmento como configurador de formas del nuevo arte y, en cierta medida, la unión de muchos fragmentos es el origen de las obras de un artista que quería abarcar todas las ramas del arte y ser, él mismo, una "obra de arte total": Kurt Schwiters. Este alemán, nacido en Hannover en 1887, cursa sus estudios en la Academia de Artes de Dresde y posteriormente inicia la carrera de arquitectura para dejarla rápidamente. Después de picotear en diversos "ismos", creó su propio movimiento artístico, su gran obra, $M E R Z$, y, dentro de ella, el MERZbau, que va creciendo día a día como agregación de múltiples fragmentos, como reciclaje de desechos, como ente 
orgánico que desarrolla sus miembros en el espacio, que lo invade, pero sin perder la unidad; el entorno transformado en obra de arte total.

Se trataba, en palabras del propio Schwitters, de "poner especialmente en relación todas las cosas del mundo" (Nobis, 1995, p. 41) y, al mismo tiempo, de crear un espacio espiritual lejos del mismo. El artista había ideado $M E R Z$ como suma de diferentes géneros artísticos, pero ya antes de ello se había sentido "seducido por la integración de la pintura abstracta y la máquina en la obra de arte total" (Schwitters, 1995, p. 51), aunque no concebía esta como "combinación momentánea de todas las artes", sino como "eliminación constante de las fronteras y la integración de todas las artes en un solo concepto" (Szeemann, 1995, p. 426).

Fritz Neumeyer va mucho más allá en sus apreciaciones sobre la obra de arte total. Partiendo de las consideraciones de Nietzche sobre la definición de cultura como "unidad de estilo artístico en todas las manifestaciones artísticas de un pueblo" (Neumeyer, 1995, p. 113) y su idea de establecer una íntima implicación entre arte y vida, llega a establecer la obra de arte total moderna en la unión entre arte e industria, fijando los comienzos de ese maridaje en la nominación de Peter Behrens como asesor artístico de las fábricas AEG en la primera década del siglo XX. Estos serían los comienzos del diseño global que se introduce dentro de la élite artística, la vida cotidiana no podía estar más unida al arte.

En Souriau se encuentra la distinción entre arte y artes, siendo estas últimas las que portan los elementos diferenciadores, mientras que el arte lleva en su esencia lo permanente. Posiblemente esta idea no se encuentre alejada de la Fenomenología de Husserl, en el sentido de la búsqueda de las esencias; en este caso, en el arte se encontraría la esencia de las artes. Souriau acude al establecimiento de una nueva disciplina, denominada estética comparada, que consolidara las bases de las correspondencias entre las artes a partir del estudio de obras desarrolladas en los distintos campos: "Las diferentes artes son como distintas lenguas, entre las cuales la imitación exige la traducción, un nuevo pensar en un material expresivo totalmente distinto, una invención de efectos artísticos, antes paralelos que literalmente análogos" (Souriau, 1998, p. 21). El estudio deberá ser riguroso mediante el empleo de términos técnicos precisos y sin la aparición de lenguajes metafóricos que conduzcan al error.

Argan da una definición parecida, ya que considera el arte "como una orquesta cuyos sonidos serían las distintas artes", siendo "legítimo el concierto de las artes, cada 
una de ellas con su propia técnica específica, pero con ciertas posibilidades de paso de una técnica a otras: ut pictura poësis" (Argan, 1987, p. 72); mientras que para Kandinsky "los elementos de las diferentes artes sólo representan una identidad totalmente esquemática. En realidad, una diferencia de «timbre» como entre los diversos instrumentos de música" (Kandinsky, 1991b, p. 33).

Souriau dota a la creación artística de verdadera entidad, le confiere una existencia propia; el artista aparece así como verdadero creador de obras en las que se ha generado "un mundo completo, con sus dimensiones espaciales, temporales, y también con sus dimensiones espirituales" (Souriau, 1998, p. 42). La obra de arte se concibe como ser único, dotado de una existencia fenomenológica, sin desdeñar el aspecto que le hace ser percibido por los sentidos: "la obra de arte no está formada por sensaciones. Está formada por cualidades sensibles" (Souriau, 1998, p. 67). En toda obra artística, es elemento importante la materia con que está ejecutada, pero no es privativo de un arte determinado una materia específica, son intercambiables entre los distintos géneros $\mathrm{y}$, en algunos casos, puede considerarse simplemente formando parte de un plano existencial que no es el de su mera existencia física. En este punto, Souriau distingue entre la existencia física, la existencia fenomenológica, la existencia "reica", o cosal, y la existencia transcendente de la obra de arte. Sobre la existencia cosal de la obra incide Heidegger ("todas las obras tienen este carácter de cosa" (Heidegger, 1988, p. 40) y establece la relación entre el material, la materia hecha forma, con que se ejecuta y la obra realizada, pero tampoco se queda en el carácter tangible de la obra de arte y, más adelante, dice: "la obra [...] es alegoría [...]. La obra es símbolo" (Heidegger, 1988, p. 41).

Souriau llega a una clasificación de artes de primer y segundo grado, en función de una organización formal inherente a la obra misma o a los seres representados en ella, que le lleva a establecer un esquema del conjunto de correspondencias que se pueden establecer entre las diversas artes, donde, en un primer nivel, existe una relación por pares, susceptible de ampliarse según un criterio de afinidades estéticas.

Mario Praz, que se interroga sobre la rigurosidad en la que se fundamenta Souriau, en su análisis de la correspondencia entre las artes, fundamenta la relación entre pintura y literatura en el uso que los pintores hacían de las descripciones de los textos literarios como inspiración para el desarrollo de sus obras, recreando en imágenes visuales la temática de los escritores, fueran estos temas religiosos, profanos o mitológicos. 
La disputa entre poetas y pintores se hace patente en el Renacimiento, ante el auge que adquiere la pintura en esta época. En el siglo XVII, sin embargo, son los paisajistas los sugeridores de los temas poéticos. Todas estas concordancias parecen muy traídas por los pelos, pero Praz persevera en su estudio haciendo un recorrido por la historia, sacando conclusiones de cada época: en el Medievo, cuando primaba el germen espiritual, la música se hace escultura y las formas abstractas constituyen el deleite del alma, que se eleva hacia el cielo a través de la arquitectura gótica; el Renacimiento, mucho más humano, emplea las proporciones geométricas, que se afilian con los intervalos musicales, y trata de potenciar la unidad de las artes; el manierismo retuerce las intenciones y las representaciones, y los juegos dialécticos aparecen en obras de distintos géneros artísticos.

En la época barroca, tensiones y contrastes crean escenografías dramáticas, donde la luz interviene de forma decisiva: el trampantojo convierte la pintura en espacio y la arquitectura se hace ficticia; la primera como prolongación de la segunda se funde con ella; y la curva adquiere en esta época su máximo auge. Por su parte, el rococó será una prolongación exaltada donde se pierde cualquier referencia geométrica, la razón deja paso a la imaginación, los temas se sobreponen, ya sea en pintura, arquitectura o literatura, y se sientan las bases de un arte no representativo.

En el siglo XVIII, la arquitectura pierde su soberanía sobre las otras artes y los edificios entran a formar parte de una escenografía. Los "arquitectos revolucionarios" juegan con el cubo, el cilindro o la esfera y los elementos literarios, las cualidades narrativas arrojan su manto sobre el arte de construir. Boulleé, por ejemplo, dará a la arquitectura una connotación de arte figurativo y sus arquitecturas parlantes son personajes en el escenario de la ciudad, y va todavía más lejos cuando dice: "Nuestros edificios públicos deberían de ser, de algún modo, verdaderos poemas” (Tafuri, 1987, p. 98); Para Francastel “el siglo XVIII será un siglo amante de la naturaleza, el paseo y la conversación. El nuevo universo de la razón y la naturaleza será imaginado y hablado antes que instaurado institucionalmente" (Francastel, 1987, p. 39).

En cuanto al siglo XIX, es la época de la desorientación, las artes parecen estar huérfanas y yerran perdidas sin encontrar más puntos de confluencia que sus interpretaciones psicológicas. Kandinsky la caracteriza "como una época que se mantiene alejada de la creación interna" (Kandinsky 1989, p. 180). Literatura y pintura, sin embargo, parecen estrechar sus vínculos y las imágenes de lo cotidiano van ganando 
terreno frente a la temática religiosa y mitológica. La técnica desborda los cauces del arte y la arquitectura se hace cada vez más arte de construir ante el impulso de los nuevos materiales que la conducen por caminos paralelos a la ingeniería. La fotografía supone un vuelco para la concepción del arte pictórico, el tema se disuelve ante la cegadora luz que conduce hasta el impresionismo y la pintura toma el mando ante las demás artes.

Schopenhauer parte de la Idea, en el sentido platónico, como configuradora de toda obra de arte, idea intuitiva, alejada del concepto, que es racional. Para él, "el fin de todas las artes es expresar Ideas, y su principal diferencia consiste en el grado de objetivación de la voluntad que cada Idea expresa, las artes, aún aquellas que más se diferencian, pueden explicarse mutuamente por comparación" (Schopenhauer, 1992, p. 200). La música es, para el pensador, la más sublime de las artes e, incomparable con respecto a las demás, la define como "lengua universal" (Schopenhauer, 1992, p. 203), "lenguaje del sentimiento y las pasiones" (Schopenhauer, 1992, p. 206), expresión de la esencia interior.

En la frontera entre los siglos XIX y XX, el Art Nouveau concilia las diferentes artes; las ondulantes líneas vegetales van entrelazando arquitectura, pintura, escultura o literatura; el trazado curvo y sinuoso remite a una vida orgánica que acaba convirtiéndose en mero recurso decorativo "desdibujando las fronteras entre los diferentes géneros artísticos. De ahí que se llegue a los «ornamentos plásticos» y a la fusión de marco y cuadro en esa unidad cargada de sentido ornamental" (Schmutzler, 1980, p. 13). Es en este período en el que gran número de artistas se dedican a diferentes géneros, pintura, poesía, música, artes decorativas, cualquiera se consideraba adecuado para la imaginación modernista. Estrechamente vinculadas se encuentran la pintura ilustrativa y decorativa del art nouveau con la literatura simbolista, al igual que la pintura y la música; Stravinsky, Scriabin y el Schönberg de los primeros años están vinculados a este movimiento con obras en las que se conjuga todo un juego de luz, color y sonido.

La creación de un entorno armonioso incitaba a los artistas vinculados a este estilo, también ellos pretendían conjugar arte y vida: "El modernismo quería convertir cada cosa de esta vida en una obra de arte" (Schmutzler, 1980, p. 39). La Maison Tassel de Bruselas, realizada entre 1892 y 1893, por Victor Horta, representa mejor que ninguna otra obra de la época la realización de este arte total: motivos decorativos que habían surgido sobre el plano adquieren dimensión en el espacio, elementos estructurales sustentantes asemejan 
raíces, troncos y ramas vegetales, convirtiendo la obra en un organismo vivo, caracterizado por el movimiento y la transparencia.

El siglo XX será ya el de la intersección de espacio y tiempo, confluencia que supone la yuxtaposición de los géneros artísticos. Por medio de la abstracción, la obra sugiere, se convierte en signo: "Mondrian, Kandinsky, Klee: [...] desarrollaron una técnica libre donde los signos mismos reemplazan a las imágenes” (Praz, 1981, p. 207). Decía el arquitecto John Hejduk que:

El pintor parte del mundo real y trabaja hacia la abstracción, y cuando termina una obra, ésta es una abstracción del llamado mundo real. El arquitecto, en cambio, parte del mundo abstracto y, debido a la naturaleza de su trabajo, tiende hacia el mundo real. El arquitecto importante es el único que, cuando ha acabado su trabajo, está tan próximo a la abstracción original como le ha sido posible (Montaner, 1993, p. 172).

El caso de Hejduk es significativo, pues él mismo ha establecido la relación directa existente entre un proyecto de vivienda de 1967 y el cuadro Fox Trot A, de Mondrian, realizado en 1927. Piet Mondrian, ligado a la revista De Stijl, fundada por Theo van Doesburg en 1917, y en la que trataba de establecerse una compenetración entre pintura, escultura y arquitectura, demuestra un inusitado interés hacia esta última. Así que, a su cuadro Fachada en marrón y gris, de 1913, sigue una serie de composiciones que inciden sobre similar formalización hasta llegar a las distintas versiones de Fachada de Iglesia, que realiza en 1914, en las que se aprecia claramente la relación existente con la realidad arquitectónica.

Mondrian, siguiendo los pasos de Kandinsky, en su escrito "El neoplasticismo en pintura”, publicado en 1917 en el número 1 de la revista De Stijl, habla de que:

Cada arte tiene su propio énfasis, su particular expresión: es la justificación de la existencia de varias artes. [...] [Además] con el avance de la cultura del espíritu, todas las artes, a pesar de sus diferentes modos de expresión, han devenido en una creación plástica de relación equilibrada y determinada (Mondrian, 1999, p. 254). Nadie parecía estar a salvo de este interés por tender lazos entre las diversas artes, e incluso entre los artistas vanguardistas rusos se pueden encontrar ejemplos de esta tendencia. Dentro de una política de realización de monumentos llevada a cabo por el Comisariado del Pueblo para la Educación, en honor de personajes o como glosa de 
actividades, realiza Vladimir Tatlin, en 1919, un Monumento a la III Internacional, donde rompe con la tradicional representación figurativa, al hacer surgir un elemento a medio camino entre la escultura y la arquitectura empleando vidrio y acero; la pieza "no sólo pretendía erigirse como una síntesis de las artes, sino de las diferentes inquietudes vanguardistas del momento y de la confluencia entre la nueva cultura del material y la plástica puramente pictórica" (Marchán Fiz, 1995, p. 185). Muestra palpable de este interés fue la creación, por parte del Ministerio de Educación, presidido por el poeta Anatoli Lunacharsky, de una Comisión de Pintura, Escultura y Arquitectura, integrada por artistas y arquitectos, entre los que destaca Alexander Rodchenko, cuya misión fue el estudio de la sintetización de las artes, para obtener como resultado una "iconografía simbólica que expresara los nuevos programas sociales" (Ikonnikov, 1991, p. 6) que recoge influencias románticas y expresionistas.

En las declamaciones dadaístas también se puede encontrar esta fusión entre diversas ramas del arte: la voz se convierte en instrumento musical, el artista con su mímica crea un ambiente teatral, al que contribuyen los espectadores que, en ocasiones, con sus gritos y sus ruidos entran a formar parte de la propia representación, ellos sirven de telón de fondo, se asimilan al coro de la puesta en escena; trajes, máscaras e iluminación generan el cuadro de este trozo de vida convertido en obra de arte, aunque le pesase a sus propios creadores; una muestra de expresividad de los que satirizaban al expresionismo, quizás porque se encontraba demasiado próximo a ellos.

En un mundo en completa ebullición, del que forma parte inseparable el arte, los distintos campos en los que este tradicionalmente se ha dividido establecen una relación que trata de unificarlos en un todo único, donde desaparezcan las fronteras. Las teorías artísticas se desplazan libremente, igual que sus autores, de una ciudad a otra, de un país a otro, y la formalización a la que se llega a veces confluye y otras se dispersa.

\section{La arquitectura como obra de arte total}

La catedral gótica, visión onírica romántica por excelencia, aparece como figura recurrente que acoge en su seno a todas las demás artes; como dice Marchán Fiz, "en esta ensoñación se absolutizan lo religioso, lo nacional y lo artístico desde la aspiración suprema a la «obra de arte total»" (Marchán Fiz, 1986, p. 68). La catedral gótica se 
interpreta como entidad única, como totalidad, haciendo abstracción de sus partes; Worringer habla de su inmaterialidad, a pesar de ser una arquitectura realizada en piedra: "La arquitectura que era arte de mampostería, se ha convertido en un arte de la construcción espiritual” (Worringer, 1973, p. 83). Formalización, estructuración y materiales se complementan para crear una atmósfera que funciona como si de una escenografía se tratase, el oficiante religioso y los que asisten a la celebración se asimilan con actor y espectadores englobados en un acto de obra de arte total, en un espacio ideal surgido del equilibrio de proporciones, de "la armonía de las partes", el espacio real deviene espacio simbólico.

Frente a la visión romántica, la visión crítica e irónica la ofrece Adolf Loos (1984) en el artículo "Vom einem armen reichen Manne", publicado por primera vez en abril de 1900 en el Neuer Wiener Tagblatt y recogido posteriormente en "Ins Leere Gesprochen 1897-1900"3 que se edita por primera vez en París en 1921. En dicho artículo, Loos narra la historia de un hombre que se ve atrapado por las ansias de controlar la obra, todo objeto que pueda situarse en ella y sus moradores, como un todo único, incluyendo los sonidos que puedan provenir del exterior, por parte del arquitecto, a quien encarga la decoración de su casa como forma de rendir pleitesía al arte.

Loos vivía la época del art nouveau, en la que se puedan encontrar formalizaciones semejantes hasta en la indumentaria; sin embargo, tampoco este hecho es aislado si se efectúa un recorrido por la historia. Mario Praz lo recoge en su libro Mnemosyne. El paralelismo entre la literatura y las artes visuales y, citando a historiadores del vestido, establece una relación directa entre el pináculo gótico y el tocado femenino de la época, o entre el efecto de claroscuro del arte barroco con las combinaciones de tejidos que se efectuaban en la confección de los atuendos.

En 1918, Guillaume Apollinaire publica el artículo “L'Esprit Nouveau et les Poètes" donde "evoca la visión poética de una síntesis de las artes que englobaría el conjunto de los fenómenos visuales y auditivos del mundo moderno" (Moos, 1977, p. 79); a finales del mismo año, Bruno Taut saca a la luz, con el apoyo del Arbeistsrat für Kunst, el Architektur - Programm, el cual inicia con estas palabras:

\footnotetext{
${ }^{3}$ El artículo, con el título, "Acerca de un pobre hombre rico", se publica en español dentro del libro de A. Loos (1984), Dicho en el vacío 1897-1900. Valencia: Colegio Oficial de Aparejadores y Arquitectos Técnicos de Murcia
} 
¡El arte! [...] ¡Algo hermoso, si existe! Pero hoy no existe arte. Las tendencias disgregadas sólo pueden reunirse en busca de la unidad bajo las alas de una nueva arquitectura, de modo que cada rama particular contribuya a la edificación. Entonces no habrá fronteras entre las artes aplicadas y la escultura o la pintura, todo será uno, edificar (Taut, 1973, p. 61).

$\mathrm{Al}$ año siguiente, Walter Gropius repetirá prácticamente las mismas palabras en el programa de la Bauhaus Estatal de Weimar, que proclamaba en su inicio: “ $¡ E l$ fin último de cualquier actividad figurativa es la arquitectura!" (Gropius, 1980, p. 40). Para Gropius, la vuelta al taller del artista suponía una forma de redención frente a la improductividad de la obra que imperaba en aquel momento, pretendía una fusión entre artesano y artista como fórmula para salir de la encrucijada y, con base en esta idea, establece el programa de la Bauhaus:

La Bauhaus se propone reunir en una unidad todas las formas de la creación artística, reunificar en una nueva arquitectura, como partes indivisibles, todas las disciplinas de las prácticas artísticas: escultura, pintura, artes aplicadas y artesanado. El fin último, aunque remoto, de la Bauhaus es la obra de arte unitaria (Gropius, 1980, p. 42).

Con estas palabras, Gropius deja traslucir su escepticismo en la consecución de una obra de arte total, considerando ésta como una utopía

En este mismo contexto, Oskar Schlemmer, aunque se mostraba totalmente contrario a esta idea de obra de arte total, escribe en su diario sobre "la voluntad de síntesis que domina el arte actual, que invoca a la arquitectura para que actúe como ordenadora de los sectores que saltaron en astillas, para reconducirlos no sólo a su propia unidad sino a una unidad universal" (Schlemmer, 1987, p. 60).

Peter Collins se muestra totalmente escéptico cuando se habla de relaciones e influencias entre los distintos géneros del arte, y cuenta la anécdota de Bruno Taut, que escribía que:

Con el debido aprecio por Le Corbusier, su mayor debilidad está en que no es sólo arquitecto, sino también un pintor abstracto y, como consecuencia de ello, confunde los problemas de la construcción con los de la pintura de estudio (Collins, 1977, pp. 290-291) 
Parece que el autor desea subscribir estas palabras, pues considera el hecho arquitectónico con unas características tan precisas que podrían verse desvirtuadas por influencias ajenas al medio y, todo ello, partiendo de la base de que la modificación del criterio estético que da lugar a una literatura "realista", donde se muestra lo peor de la sociedad, supuso una influencia sobre la arquitectura de finales del siglo XIX que sirve de base a las formas abstractas surgidas a comienzos del XX.

Las teorías de Kandinsky que llevan a las formas abstractas no representativas y, por tanto, a un tipo de arte carente de todo fin práctico, podría significar, según algunos autores, aplicándolo a la arquitectura, la aparición de edificios cuyo componente esencial sea su valor estético, cuyas cualidades de uso y funcionales sufrirían una pérdida total. No obstante, la arquitectura, en su conjunto, ha seguido cumpliendo en mayor o menor medida, o de mejor o peor forma, la función que siempre se le ha encomendado. Independientemente de qué, lo que sí sigue subsistiendo es la disensión de pareceres en lo que se refiere al ideal de belleza clásica. La tendencia a una geometrización de la obra arquitectónica, el empleo de "formas puras", el uso del cubo, la pirámide, el cono o la esfera no consiguieron alejar a la arquitectura del laberinto.

Alvar Aalto cuenta el proceso creativo de sus obras a partir de dibujos imaginarios $\mathrm{y}$ abstractos de los que surgen las plantas y secciones generadoras de sus edificios. El propio Aalto, artista poco dado a la literatura sobre las artes, participa, en 1947, en el debate sobre la arquitectura y el arte en un artículo publicado por la revista Domus. En este documento, el autor, fundamentalmente arquitecto pero que no despreciaba la realización de obras de otros campos del arte, considera "que las formas de arte concreto han dado un fuerte impulso a la arquitectura moderna, en un modo, cierto es, indirecto, si bien irrefutable" (Aalto, 1978, p. 38). En su opinión, "la arquitectura y las demás artes han tenido el mismo punto de partida, punto de partida que, sin duda, es abstracto, pero que, al mismo tiempo, está influenciado por todos los conocimientos y los sentimientos acumulados en nosotros" (Aalto, 1978, p. 41).

Si siempre se ha tendido a considerar la influencia que la pintura, la escultura $u$ otras artes han tenido sobre la arquitectura, el campo de investigación en sentido contrario ha sido más limitado, quizás porque el estudio de la obra arquitectónica presenta una mayor complejidad y son necesarios unos conocimientos más amplios para llegar a una visión global del edificio, dada la gran variedad de puntos de vista desde el que puede ser analizado. Collins apunta este campo al hablar de Franz Lloyd Wright, de la forma de 
concepción espacial de algunos de sus edificios y su posible influencia sobre los artistas de De Stijl (Collins, 1977, pp. 286).

En el momento actual es, en muchas ocasiones, la filosofía, las ideas filosóficas, las que sirven de referente para el desarrollo de la idea artística: la obra quiere convertirse en reflejo de una teoría, ya no se trata solamente de "la búsqueda de ritmo y la construcción matemática y abstracta" (Kandinsky, 1991a, p. 50), se pretende lograr una síntesis de obra y pensamiento. De este parentesco entre filosofía y arquitectura hablaba ya, en 1920, Paul Bommersheim en el artículo "Filosofía y arquitectura", publicado en el fascículo 10 de Frühlicht; para él:

Filosofía, arquitectura, comunidad son tres principios absolutos; y lo que los unifica es la religión", [siendo la] arquitectura [...] una triple totalidad: ella reúne en sí todas las artes - la pintura, la escultura, el arte de construir, el arte de los jardines. Es la unidad entre naturaleza y arte, porque expresa la naturaleza en forma artística (Bommersheim, 1974, p. 47).

El autor ve en la filosofía un punto de confluencia de todo el saber, estableciéndola como fusión del mundo y el alma y, desde esa visión, establece la analogía con el arte, como confluencia de las artes particulares, que surgen como resultado de su desarrollo.

Bajo un prisma de misticismo, relaciona la arquitectura, que da cobijo a la vida humana, con lo sobrenatural. Desde una visión premonitoria establece que "el arquitecto puede encontrar en la clara estructura de un sistema filosófico el entusiasmo de la creación y la inspiración para nuevas formas arrolladoras" (Bommersheim, 1974, p. 48). En la búsqueda y consecución de lo "absoluto" se encuentra, para Bommersheim, la base de la interrelación entre la arquitectura y las otras artes, siendo la filosofía la que acude en su ayuda en este afán. La arquitectura se convierte en síntesis de todas las artes a partir de su contenido simbólico.

Para Schopenhauer, en su obra cumbre, El mundo como voluntad y representación, publicada por primera vez en 1819, “el arte arquitectónico se diferencia [de las otras artes en cuanto] el artista coloca el objeto ante el espectador, haciendo que el objeto real individual exprese su propia esencia de una manera distinta y acabada" (Schopenhauer, 1992, p. 175); el filósofo considera el ornamento como adorno suplementario e incide en la importancia que sobre la obra arquitectónica presenta la luz, luz cambiante ante la cual el edificio ofrece múltiples facetas. 
El arquitecto expresionista Hans Poelzig decía que "la arquitectura es música congelada", que el ritmo y la musicalidad en la construcción vienen determinados por un uso adecuado de los elementos constructivos; se trataba de dejar hablar a los materiales. En sus palabras:

La música es el arte menos ligado a la tierra, la arquitectura la que lo está más. Pero entre todas las artes figurativas es la más abstracta, puede dar los sonidos más puros y al mismo tiempo más místicos y puede transfigurar la materia en la forma más pura (Poelzig, 1978, p. 229).

Por su parte, para Pehnt, la Gesamtkunstwerk u obra de arte total tenía un doble significado en el contexto del expresionismo, significaba la unión de todas las artes en la arquitectura, pero también podía referirse al entorno total que incidía simultáneamente sobre varios sentidos del hombre: "La arquitectura expresionista apela al ojo, al tacto, al sentido sinestésico. Despierta asociaciones heterogéneas tanto en el tiempo como en el espacio" (Pehnt, 1975, p. 19). También otro arquitecto ligado al ambiente expresionista, Hans Scharoun, en la conferencia "Ideas sobre la escenografía moderna", pronunciada en Königsberg alrededor de 1921, habla de la relación entre las artes:

Arquitectura significa «Conductora de las Artes», y ésta es la denominación que la arquitectura ha merecido en todos los períodos culminantes de la Civilización. Bajo su dirección las artes particulares se reunieron para formar una imagen global homogénea. Ahora, en cambio, dejamos atrás una época en la que el pensamiento técnico por un lado, la interpretación desde un punto de vista técnico de lo contemplado por el otro, y en conclusión, la actitud superficial del espectador, fueron las razones de que en las relaciones de las artes entre sí se afianzarán lo particular frente a la unión, la fragmentación frente a la síntesis (Scharoun, 1993a, p. 55).

Scharoun consideraba que las artes plásticas habían seguido un camino que conducía a esa síntesis, no así la arquitectura, dependiente de "patrones de belleza"; en su texto reivindica el arte escenográfico como "actividad artística en sí", influido, en su formalización, por el momento en que se realiza:

$\mathrm{Y}$ es este ideal del momento, es decir, la correspondiente forma de cultura dominante, lo que da un valor interior a la Obra de Arte Total, y cuya carencia, 
por otra parte, sustituye la obra de arte conclusa por el experimento, y así por lo poco artístico (Scharoun, 1993a, p. 56).

Además, Scharoun refiere a los materiales que utiliza cada una de las artes y considera que pintura y escultura se encuentran indisolublemente unidas con aquel con el que se realiza la obra, mientras que "la arquitectura es la música absoluta". Escribe:

La arquitectura moderna utiliza nuevamente, como la de la antiguiedad, los materiales de construcción en un sentido sensorial; es decir, es consciente del peso de la piedra y del molde de hormigón. Pero al mismo tiempo desmaterializa el material, al igual que el arte gótico, lo espiritualiza, como podemos observar, por ejemplo, en recientes creaciones de edificaciones fabriles. Espiritualiza el material utilizando las fuerzas intrínsecas para, partiendo de la estética de las mismas, llegar de nuevo al espacio, que está relacionado de una manera viva con el entorno (Scharoun, 1993a, p. 55).

Las alusiones a la música aparecen en varios de sus escritos en los que establece comparaciones entre ella y las combinaciones espaciales de la obra arquitectónica, en como los espacios pueden disponerse simétrica o asimétricamente, siguiendo secuencias, según acordes o discordancias; cada uno de los espacios, como los instrumentos de una orquesta, sirven al conjunto sin dejar de tener valor como elemento individual.

\section{Teatro y cine: unidos por el espacio y el tiempo}

Baudelaire decía que el propio Wagner consideraba "el arte dramático, esto es, la reunión, la coincidencia de varias artes, como el arte por excelencia, el más sintético y el más perfecto" (Arnaldo, 2000, p. 19). La obra de arte total wagneriana parte de la configuración del propio teatro; la concepción arquitectónica, tanto del escenario como del patio de butacas, predispone al público a integrarse dentro de la escena que está teniendo lugar en el momento de la representación. En palabras de Wagner:

Apenas haya ocupado su puesto, el espectador se encuentra en un verdadero y propio «theatron», es decir, en un lugar destinado exclusivamente al mirar, y a mirar en la dirección hacia la que le dirige su puesto. Entre el espectador y la imagen para mirar no se encuentra nada aparentemente visible, sólo una distancia 
que un artificio arquitectónico mantiene casi suspendida entre los dos proscenios, y que, alejando la imagen del espectador, la muestra en la inaccesibilidad de una visión onírica, mientras la música, emergiendo misteriosamente del «abismo místico», asemeja a los vapores que bajo el sitial de la Pizia surgen del sagrado seno de Gaia, introduciéndolo en una condición estática de clarividencia, por la cual el cuadro escénico contemplado se vuelve para él la imagen más fiel de la vida misma (citado en Posener, 1989, p. 15).

Las creaciones de Wagner son consideradas “obras monumentales” por algo más que la creación del espacio escénico por medio de recursos arquitectónicos. Kandinsky establece la consecución de este tipo de obra a partir de la unión orgánica de las partes aisladas, la música debe ir unida a la acción dramática, no funcionar como simple acompañamiento; sin embargo, critica en la obra wagneriana la repetición de un motivo musical que precede al héroe y hace predecible su aparición en escena, así como no haber sabido sacar partido del "color y la forma pictórica" (Kandinsky, 1989, p. 184) en la creación escenográfica.

Ferviente admirador de Wagner, Kandinsky pretendía llegar a conseguir un grado de abstracción tal que eliminara de la obra cualquier efecto narrativo; Arnaldo establece la relación entre ambos como "intención de sugestionar con una realidad que se materializa desde lo inmaterial y que se autoatribuye valores absolutos" (Arnaldo, 2000, p. 37). Wassily Kandinsky, artista y teórico que hizo posible un cambio en la forma de ver el arte del siglo XX, "creía que la forma del arte del futuro reuniría y trascendería a todos los medios individuales, creándose una síntesis gloriosa" (Whitford, 1991, p. 95); también había hecho incursiones en el campo escenográfico con Sonoridad amarilla, publicado en 1912 dentro de El Jinete Azul, Sonoridad verde o Negro y blanco, conjunto de obras en las que se aúnan la pintura, la música y la danza. Su deseo de interrelación lo lleva, en ocasiones, a titular sus cuadros aludiendo de forma clara al mundo musical, al tiempo que sus cualidades sinestésicas, que le hacían asociar colores a los sonidos, le servirán desde joven para enlazar música y pintura y crear en su mente las obras musicales a la manera de cuadros coloristas. En Sonoridad amarilla, concebida como obra de arte total, la escenografía se crea a partir del color, la iluminación, los cantos y la música que suenan como telón de fondo y que, en algunos momentos, entran en lid hasta que llega el silencio. 
En su interés por el teatro, Kandinsky centra su atención en la creación de obras que le permitan llegar a conseguir una obra de arte total donde confluyan "1. el tono musical y su movimiento, 2.el sonido corporal-espiritual y su movimiento expresado por hombres y objetos” y “3. el tono cromático y su movimiento”, tratando de conseguir un "complejo de las experiencias interiores (vibraciones anímicas) del espectador" (Kandinsky, 1989, p. 188) que genere el verdadero drama.

Entre los textos que componen el El Jinete Azul se encuentra también “Prometheus, de Skriabin”, escrito por Leónidas Sabaneiev (1989), compositor ruso. Allí, el autor señala la liturgia como el germen del nacimiento de la obra de arte total, actos religiosos en los que sonido, movimiento, olor, color se unen en un todo armónico en función de una actividad mística, recogiendo, aunque desde un punto de vista diferente, aquella idea de consideración de la catedral gótica como "obra de arte integral". Nombrando a Wagner como sugeridor de la idea de la reunificación de las artes, para él, sin embargo, es la figura de Skriabin la que de una forma más precisa la concibe. Establece una jerarquización de las artes, unas principales y otras subordinadas que, actuando como caja de resonancia, resaltan las primeras. En el Prometheus, Skriabin llega a una fusión orgánica entre la música y su correspondencia dentro de una armonía cromática; a cada nota aparece asociado un color, sugerido por la iluminación.

Kandinsky retoma la idea de lo religioso como arte total en sus Cursos de la Bauhaus del semestre de verano de 1925 en los que dice: "La forma más pura de síntesis: la Iglesia. (Edificio, pintura, escultura, música, movimiento del oficiante [danza + poesía])" (Kandinsky, 1991b, p. 24), y más adelante señala que "la fe, en todas las religiones, crea: arquitectura, escultura, pintura, danza, poesía, música" (Kandinsky, 1991b, p. 28).

Todo El Jinete azul responde a un intento de hacer confluir las diversas artes en un empeño común, empeño que, en el caso de Kandinsky, surge de una "necesidad interior" y que tiene como fin una nueva concepción de la existencia, la unión de arte y vida. También en su libro De lo espiritual en el arte, editado por vez primera en 1912, dedica el Capítulo IV, "La pirámide", al tema de la interrelación de las artes; parte de la idea de que cada arte posee unos medios que le son propios y son, precisamente, estos medios y materiales específicos con que cada artista trabaja e investiga los que conducen al conocimiento de un "valor interno" que es donde se establece la confluencia con las demás artes. Juega aquí Kandinsky, como lo hará posteriormente al titular sus cuadros 
mediante términos antagónicos, con contradicciones que supera siempre con esa llamada al "empeño interior común”.

En cuanto al arquitecto Hans Scharoun, su interés por el teatro se centrará en la configuración espacial de la escena, que estudiará en sus proyectos para edificios teatrales la conformación de aquella y la interrelación con el espectador a partir de la disposición de las butacas, sin olvidar lo que significa la representación en sí, en la que, desde un espíritu humanista, reivindica la figura del actor como el "centro y el cerebro del teatro" (Scharoun, 1993b, p. 54).

Pero es quizás en el cine, el llamado séptimo arte, donde mejor se podría aplicar el término de obra de arte total. En sus comienzos, la ideología de una figura como Thomas Alva Edison (aun jugando un papel marginal en su invención, como refiere Nöel Burch) representa, en palabras de Burch, la:

Prolongación de la fantasía wagneriana, de esa ideología del Gesamtkunstwerk por la que más de un artista, mediante formas equivalentes (Scriabin, pero también Kandinsky), cree que puede «tender a la unidad y a la multiplicidad, dar un equivalente de lo que hace la naturaleza, dotar a la obra de arte de una cuarta dimensión, la dimensión cósmica» (1991, p. 45).

Los sueños de algunos arquitectos expresionistas se llevarían a cabo en un mundo de ensueño, el del cine. Los arquitectos se convierten en escenógrafos para tener la posibilidad de construir sus obras, arquitecturas de cartón piedra, o pintadas, que, por efecto de la iluminación o el enfoque, se convierten en fachadas configuradoras de calles y en espacios en los que se desarrolla la acción; arquitecturas parlantes que ayudan en la comprensión del mensaje de la película a la par que los gestos forzados y patéticos de unos actores que tienen que dejar oír su voz en un cine todavía mudo.

Hans Poelzig crea los decorados para la segunda versión que su amigo Paul Wegener realizará de El Golem, basada en la historia de un rabino cuyos poderes mágicos dan vida a un gigante de barro. La acción se desarrolla en el barrio judío de Praga y Poelzig realiza un decorado tridimensional de calles tortuosas acosadas por las edificaciones irregulares de líneas quebradas y angulosas que recuerdan el estilo pictórico de los componentes de Die Brücke: cubiertas, escaleras, puertas, ventanas, todo se retuerce en un deseo de expresividad, de invitación al movimiento; no hay elementos que puedan sugerir estatismo, todo es un continuo fluir. El decorado tridimensional de $E l$ 
Golem supone una transformación evidente de El Gabinete del Dr. Caligari, idea de Reimann, Röhrig y Warm, realizado todo él a base de lienzos pintados, incluso los propios efectos de luces y sombras, en un intento de eliminar todo naturalismo y donde las arquitecturas reproducidas presentaban quiebros rotundos y se inclinaban sobre el espacio de la acción.

A todo este mundo de sueño no podía substraerse Bruno Taut, quien propone, como obra de realización colectiva entre los miembros de La Cadena de Cristal, una película: Die Galoschen des Glücks (Los zuecos de la fortuna), basada en un cuento de Andersen. Será el primer intento de Taut en el mundo de la cinematografía. Las distintas escenas estaban pensadas para enlazar todos los eslabones de la cadena, cada miembro del grupo debería ocuparse de una de ellas, estableciendo secuencias encadenadas donde la palabra no tiene lugar, son solo las imágenes las que muestran el argumento. En la breve introducción dice Taut: "El arte es arquitectura, porque es la más pura imagen del movimiento" (Taut, 1984, p. 147); una arquitectura que aparece latente pero no expresa en la acción, acción que es recorrido del personaje, proletario cargado de desesperación en busca de un ideal que se hace visible al probarse los zuecos dispuestos en el camino, ideal representado por una arquitectura que nace de la tierra, arquitectura de cristal refulgente que se vuelve fuego cuando la acción transcurre un siglo más tarde. Visiones del futuro propias de un cine de ciencia-ficción, cambios de época propios de "El túnel del tiempo", zapatos que transportan a un año determinado, en un recorrido circular que devuelve al personaje al año inicial, pero a un paisaje campesino alegre y feliz, con edificaciones tradicionales, donde el sol es la fuente de los destellos producidos por el cristal del sueño.

El otro proyecto de Taut será Der Weltbaumeister (El constructor del mundo), subtitulado "Espectáculo arquitectónico para música sinfónica", dedicado al espíritu de Paul Scheerbart. Aunque concebida como obra teatral, su estructuración se adapta mejor a la cinematografía, ya que se trata de una sucesión de imágenes, formas que, conforme surgen y se transforman, configuran piezas arquitectónicas. Desde un escenario vacío con un único sonido musical, las formas van naciendo; son formas que semejan un pináculo que, a continuación, se desvela como de una torre de catedral gótica con sus arbotantes ligeros y, llegados a la base de la construcción, esta parece estallar, por lo que introduce al espectador en un espacio de elevadas naves eclesiales donde tañen campanas y la luz se vuelve iridiscente; formas que se atomizan desapareciendo en un vacío obscuro hasta 
plagarse de una multitud estrellada, de la que una se destaca y conduce de nuevo a la tierra; ciclo de agua y de estaciones que dan lugar al nacimiento de "LA CASA" (Taut, 1997, p. 215), casa de cristal reflejo de una arquitectura que se funde con el universo. En la obra el hombre ha desaparecido y el mismo Taut, en el epílogo titulado "Sobre teatro y música", habla de "una acción basada en la lógica interna y en la causalidad y cuyo vehículo no es la persona, sino el escenario entero [...] Proyección de nuestra existencia humana en el universo con el deseo de perdernos en él” (Taut, 1997, p. 228).

El decorado y, en su conjunto, toda la escenografía, incluido el vestuario de los actores, trataban de generar una atmósfera determinada en la que se viera envuelto el espectador. Se volvía a la idea de obra de arte total, de aunar esfuerzos en pos de la obtención de un ideal común; las ideas gótico medievales se instalaban, también, en el espacio cinematográfico y la catedral gótica, "catedral de cristal" expresionista, transmitía sus guiños al espectador. Como escribe Vila: "Cine y arquitectura coinciden en la utopía de la producción de un espacio simbólico" (1997, p. 170).

En el cine, arte del espacio y arte del tiempo, se unen todos los elementos que pueden configurar una obra de arte: color, música, sonido, arquitectura, iluminación, fotografía, tiempo, movimiento; y el equilibrio de todos ellos puede convertir una película en una obra maestra, aunque nunca llegará a "realizar la fantasía suprema: suprimir la muerte" (Burch, 1991, p. 39).

La búsqueda de la perfección de la obra alentaba a todos los artistas independientemente de su área de trabajo, pretendían confluir en una obra de arte total que sobrepasara lo terrenal; el mundo de la metafísica subyacía bajo ese manto de creatividad. Superadas algunas ideas que se habían considerado inamovibles en el mundo de la ciencia, los artistas se alineaban con los investigadores en la búsqueda de un ideal que transcendiera más allá de su imaginación. 


\section{Referencias bibliográficas}

Aalto, A. (1978). La humanización de la Arquitectura. Barcelona: Tusquets Editor.

Argan, G. C. (1987). "El valor de «la figura en la pintura» neoclásica" (1971). En VV.AA., Arte, arquitectura y estética en el siglo XVIII (pp. 71-85). Madrid, España: Ediciones Akal.

Arnaldo, J. (2000). Ópera, drama y cosmorama: Wagner y la cualidad panóptica del arte total. La balsa de la medusa, (53/54), 19-40.

Bommersheim, P. (1974). "Filosofía y arquitectura". En G. Samonà (Ed.) 1920-1922 Frühlicht. Gli anni dell'avanguardia architetonica in Germania (pp. 47-51). Milano: Gabriele Mazzotta editore

Burch, N. (1991). El tragaluz del infinito. Madrid: Ediciones Cátedra.

Collins, P. (1977). Los ideales de la arquitectura moderna: su evolución (1750-1950). Barcelona: Gustavo Gili.

Fagiolo, M. (1977). "Los grandes iniciados. El revival Rose + Croix en el período simbolista”. En G. C. Argan et al., El pasado en el presente. El revival en las artes plásticas, la arquitectura, el cine y el teatro (pp. 95-118). Barcelona: Gustavo Gili

Francastel, P. (1987). "La estética de las luces" (1963). En VV.AA., Arte, arquitectura y estética en el siglo XVIII (pp. 15-55). Madrid, España: Ediciones Akal

Gropius, W. (1980). "Programa de la Bauhaus Estatal de Weimar”. En Wingler H.M., La Bauhaus. Weimar, Dessau, Berlín 1919-1933 (40). Barcelona: Gustavo Gili

Heidegger, M. (1988). Arte y poesía. México: Fondo de Cultura Económica.

Ikonnikov, A. (1991). Años de efervescencia. El nacimiento de la arquitectura soviética. A\&V Monografías de Arquitectura y Vivienda, (29), 6.

Kandisnky, W. (1991a). De lo espiritual en el arte. Barcelona: Editorial Labor.

Kandinsky, W. (1991b). Cursos de la Bauhaus. Madrid: Alianza Editorial.

Kandinsky, W. (1989). "Sobre la composición escénica”. En Kandinsky, W y Marc, F. (Ed.) El Jinete Azul (pp. 177-193).Barcelona: Ediciones Paidós

Loos, A. (1984). Dicho en el vacío 1897-1900. Valencia: Colegio Oficial de Aparejadores y Arquitectos Técnicos de Murcia. 
Marchán Fiz, S. (1986). Contaminaciones figurativas. Madrid: Alianza Editorial.

Marchán Fiz, S. (1995). Las vanguardias históricas y sus sombras (1917-1930). Madrid: Editorial Espasa Calpe.

Mondrian, P. (1999). “El Neoplasticismo en pintura (1917-1918)”. En A. González García, F. Calvo Seraller y S. Marchán Fiz (Eds.), Escritos de arte de vanguardia 1900/1945 (pp. 252-256). Madrid: Ediciones Itsmo

Montaner, J. M. (1993). Después del movimiento moderno. Arquitectura de la segunda mitad del siglo XX. Barcelona: Gustavo Gili.

Moos, Stanislaus von. (1977). Le Corbusier. Barcelona: Editorial Lumen.

Nakov, A. (1989). “La revelación elemental”. VV.AA, Dadá y constructivismo [catálogo de exposición] (pp.13-24.. Madrid: Museo Nacional Centro de Arte Reina Sofía

Neumeyer, F. (1995). Mies van der Rohe. La palabra sin artificio. Reflexiones sobre arquitectura 1922/1968. Madrid: El Croquis Editorial.

Nobis, B. (1995). "Poner en relación todas las cosas del mundo". En VV.AA., Kurt Schwitters [catálogo de exposición] (pp. 38-41). Valencia: I.V.A.M. Centre Julio González

Nolde, E. (1999). “El color como vibración”. En A. González García, F.Calvo Serraller y S. Marchán Fiz (Eds.) Escritos de arte de vanguardia 1900/1945 (pp. 100-101). Madrid: Ediciones Itsmo.

Pehnt, W. (1975). La arquitectura expresionista. Barcelona: Gustavo Gili.

Poelzig, H. (1978). “Costruire oggi (1922)”. En J. Posener (Ed.) Hans Poelzig. Scritti e opera (pp. 217-242). Milano: Franco Angeli Editore.

Posener, J. (1989). La construzione del teatro a Berlino da Gilly a Poelzig. Zodiac, 2 (2. semestre), 6-43.

Praz, M. (1981). Mnemosyne. El paralelismo entre la literatura y las artes visuales. Madrid: Taurus Ediciones.

Rimbaud, A. (1985). Una temporada en el infierno. Iluminaciones. Carta del vidente. Barcelona: Taifa Literaria.

Sabaneiev, L. (1989). "Prometheus, de Skriabin". En W. Kandinsky y F. Marc (Eds.), El Jinete Azul (pp. 109-123). Barcelona: Ediciones Paidós 
Samonà, G. (Ed.). (1974). 1920-1922 Frühlicht. Gli anni dell'avanguardia architetonica in Germania. Milano: Gabriele Mazzotta editore.

Scharoun, H. (1993a). “Gedanken über das moderne Bühnenbild”. En A. Wendschuh (Ed.) Hans Scharoun. Zeichnungen, Aquarelle, Texte (pp. 55-62). Berlin: Schriftenreihe der Akademie der Künste Band 22

Scharoun, H. (1993b). “1925, Antrittsvorlesung an der Staatliche Akademie für Kunst und Kunstgewerbe, Breslau”. En P. Pfankuch (Ed.) Hans Scharoun. Bauten, Entwürfe, Texte (pp. 48-54). Berlin: Schriftenreihe der Akademie der künste, Band 10

Schlemmer, O. (1987). Escritos sobre arte: pintura, teatro, danza. Cartas y diarios. Barcelona: Ediciones Paidós Ibérica.

Schmutzler, R. (1980). El modernismo. Madrid: Alianza Editorial.

Schopenhauer, A. (1992). El mundo como voluntad y representación. México: Editorial Porrúa.

Souriau, É. (1998). La correspondencia de las artes. Elementos de estética comparada. México: Fondo de Cultura Económica.

Schwitters, K. (1995). "Kurt Schwitters por sí mismo: Origen y desarrollo”. En VV.AA., Kurt Schwitters [catálogo de exposición] (p. 51). Valencia: I.V.A.M. Centre Julio González

Szeemann, H. (1995). "La inmortalidad no es un asunto de cualquiera”. En VV.AA., Kurt Schwitters [catálogo de exposición] (pp. 425-435). Valencia: I.V.A.M. Centre Julio González

Tafuri, M. (1987). “Símbolo e ideología en la arquitectura de la Ilustración” (1964). En AA.VV., Arte, arquitectura y estética en el siglo XVIII (pp. 87-106). Madrid, España: Ediciones Akal

Taut, B. (1973). “1918 Un programa para la arquitectura”. En U. Conrads (Ed.) Programas y Manifiestos de la Arquitectura del Siglo XX (pp. 61-66). Barcelona: Editorial Lumen. 
Taut, B. (1984). "Los zuecos de la suerte". En M. Tafuri, La esfera y el laberinto. Vanguardias y arquitectura. Piranesi a los años setenta (pp. 146-150). Barcelona: Gustavo Gili.

Taut, B. (1997). Escritos 1919-1920. Madrid: El Croquis Editorial.

Vila, S. (1997). La escenografía. Cine y arquitectura. Madrid: Ediciones Cátedra.

Whitford, F. (1991). La Bauhaus. Barcelona: Ediciones Destino.

Wingler, H. M. (1980). La Bauhaus. Weimar, Dessau, Berlín 1919-1933. Barcelona: Gustavo Gili.

Worringer, W. (1973). La esencia del estilo gótico. Buenos Aires: Ediciones Nueva Visión SAIC.

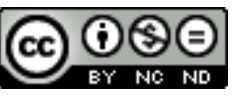

Esta obra está bajo una licencia de Creative Commons Reconocimiento-NoComercial-

$\underline{\text { SinObraDerivada } 4.0 \text { Internacional }}$ 